\title{
Alteraciones estructurales del tejido óseo en ratas tratadas con tetratiomolibdato de amonio*
}

\author{
Brem, J.J. ${ }^{1}$; Trulls, H.E. ${ }^{1}$; Sánchez Negrette, M. ${ }^{2}$; Ortíz, M.L. ${ }^{1}$ \\ ${ }^{1}$ Laboratorio de Análisis Físico-Químicos anexo a la Cátedra de Biofísica, ${ }^{2}$ Cátedra de Patología General y \\ Sistemática, Facultad de Ciencias Veterinarias, Universidad Nacional del Nordeste, Sargento Cabral 2139, \\ Corrientes (3400), Argentina. E-mail: jjbrem@vet.unne.edu.ar.
}

\begin{abstract}
Resumen
Brem, J.J.; Trulls, H.E.; Sánchez Negrette, M.; Ortíz, M.L.: Alteraciones estructurales del tejido óseo en ratas tratadas con tetratiomolibdato de amonio. Rev. vet. 20: 1, 25-30, 2009. El tetratiomolibdato (TTMo) se sintetiza en los pre-estómagos de los rumiantes por reacción del molibdeno con los sulfuros producidos por reducción bacteriana de los elementos azufrados de la dieta. TTMo sería el responsable tanto del bloqueo de la absorción del cobre como de su posterior utilización tisular, provocando una deficiencia secundaria del mismo. El objetivo del trabajo fue verificar el efecto del TTMo de amonio sobre la histología de huesos largos en este modelo experimental con el fin de aportar información acerca de la fragilidad ósea que presentan los rumiantes con molibdenosis. Se utilizaron 30 ratas Wistar de sexo macho, de 80 a 90 días de edad, agrupadas en forma aleatoria en lotes testigos y tratados, conformados con 15 animales cada uno. Estos últimos recibieron $54 \mathrm{mg} / 1$ de TTMo con el agua de bebida durante 100 días y, teniendo en cuenta el contenido de $\mathrm{Cu}$ y Mo de la dieta y la cantidad de agua y alimento consumido, el lote tratado fue sometido a un desafío de 40 ppm de Mo. Los animales mostraron sintomatología clínica claramente compatible con una deficiencia secundaria de Cu por molibdenosis. Las lesiones más importantes observadas en el tejido óseo de los animales tratados consistieron en engrosamiento del cartílago de crecimiento, con masas de condrocitos hipertróficos y falta de distribución ordenada de células en forma columnar. El tejido subperióstico mostró un incremento de espesor y hemorragias en toda la extensión de diáfisis y metáfisis. También se observó falta de reemplazo del cartílago y hueso inmaduro por tejido óseo maduro, acompañado por abundante producción de tejido fibroso, alterándose así la estructura ósea normal. Tales lesiones pudieron ser provocadas por reacciones tisulares de expansión transversal metafisiaria por una mayor deformabilidad ósea frente al desafío de cargas que el hueso debió soportar.
\end{abstract}

Palabras clave: rata, amonio tetratiomolibdato, deficiencia de cobre, daño óseo.

\begin{abstract}
Brem, J.J.; Trulls, H.E.; Sánchez Negrette, M.; Ortíz, M.L.: Osseous tissue damage in rats treated with ammonium tetrathiomolybdate. Rev. vet. 20: 1, 25-30, 2009. Ammonium tetrathiomolybdate (TTMo) is synthesized by ruminants in their pre-stomach by means of the reaction of molybdate with sulfides which are produced by bacterial reduction from the sulfurous elements from the diet. TTMo would be responsible either for the blockage of copper absorption as well as for its later tissular use, leading to a secondary copper deficiency. The aim of this work was to demonstrate the effect of TTMo on the histology of osseous tissue from large bones in this experimental model to gather information regarding bone fragility of ruminants with molybdenosis. Thirty male Wistar rats 80-90 days of age, grouped at random in control and treated lots, 15 animals each, were used. The latter group received $54 \mathrm{mg} / \mathrm{l}$ of TTMo with drinking water during 100 days. Considering the content of $\mathrm{Cu}$ and Mo from the diet and the intake of water and food, the treated group was submitted to a challenge dose of $40 \mathrm{ppm}$ of Mo. Animals showed clinical symptomatology compatible with a secondary copper deficiency. The most important injuries observed in osseous tissue of treated animals consisted in thickening of the growth cartilage, hipertrophic condrocites and disorder in column cells. The subperiostic tissue showed an increase of thickness and
\end{abstract}

Recibido: 18 de mayo 2009 / Aceptado: 29 de junio 2009

* Este trabajo es parte de la tesis doctoral del Dr. Juan José Brem en la Facultad de Ciencias Veterinarias de la Universidad Nacional de Buenos Aires. 


\begin{abstract}
hemorrhagic areas in diafisys and metafisys as well. A lack in the replacement of cartilage and immature bone by mature bone tissue, together with a high production of fibrous tissue were observed. This indicates an alteration of the normal structure of bones. These morphologic lesions could be caused by tissue reactions of transverse metaphyseal expansion as a consequence of high deforming forces on bones.
\end{abstract}

Key words: rat, ammonium tetrathiomolybdate, copper deficiency, osseous damage.

\section{INTRODUCCIÓN}

Un disturbio metabólico muy frecuente es el ocasionado por un exceso de molibdeno en las pasturas, cuyo grado de tolerancia varía según las especies, siendo el rumiante el más sensible. La molibdenosis es también conocida con el nombre de "hipocuprosis secundaria", "deficiencia secundaria de cobre" o "deficiencia condicionada de cobre" ${ }^{10,28,32,33}$, y afecta la producción de carnes rojas en grandes regiones de nuestro país y del mundo.

Los responsables de la intoxicación son los tiomolibdatos, especialmente tetratiomolibdatos (TTMo) formados en el rumen como productos de reacción del Mo con los sulfuros originados por reducción bacteriana de los compuestos azufrados de la dieta. Estos compuestos serían los responsables del bloqueo del cobre, tanto de su absorción a nivel digestivo como de la utilización tisular de lo absorbido, explicando la menor tolerancia del rumiante respecto a los monogástricos

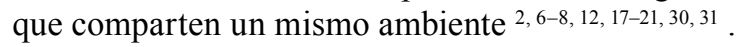

En el tejido óseo, el cobre juega un rol esencial en la función de enzimas involucradas en la formación del colágeno, y por ende en la formación de la matriz orgánica del hueso. La integridad estructural del colágeno depende del entrecruzamiento entre sus precursores, requiriendo para ello de la acción de la peptidil-lisiloxidasa, enzima cobre-dependiente que transforma la función $\varepsilon$-amina en $\varepsilon$-aldehído de los residuos de lisina de colágeno y elastina, con el propósito de formar uniones cruzadas ${ }^{3,26}$.

En rumiantes alimentados sobre pasturas deficientes en cobre se han observado fracturas espontáneas de huesos, no habiéndose siempre evidenciado correlación entre la concentración de cobre óseo y la severidad de las lesiones ${ }^{23}$. Cuando se alimentaron vacas con dietas bajas en cobre se observó una osificación endocondral conservada de la placa de crecimiento, presumiendo que la deficiencia de cobre inducida por molibdeno en el bovino no es el mismo síndrome que la deficiencia primaria de cobre en rumiantes y cerdos, que está caracterizado por una actividad osteoblástica deprimida y osteoporosis.

El objetivo del trabajo fue verificar los efectos del TTMo de amonio sobre los huesos largos de ratas, animales utilizados como modelo experimental para obtener información acerca de la fragilidad ósea que padecen los rumiantes con molibdenosis.

\section{MATERIAL Y MÉTODOS}

Síntesis de tetratiomolibdato (TTMo) de amonio: fue sintetizado in-vitro a partir de heptamolibdato de amonio disuelto en amoníaco, burbujeado con $\mathrm{H}_{2} \mathrm{~S}$ proveniente de un aparato de Kipp mediante la acción del ácido clorhídrico diluido sobre piedras de sulfuro férrico (piritas). El producto fue caracterizado por absorción espectral en UV/visible con un monitoreo de densidades ópticas entre 200 y $530 \mathrm{~nm}$, con intervalos de $5 \mathrm{~nm}$. El grado de pureza fue corroborado por los valores de absorbancia obtenidos en los tres picos característicos de esta sustancia $(220,320$ y $470 \mathrm{~nm})$.

Animales y muestreos: se utilizaron ratas machos de la cepa Wistar de 80 a 90 días de edad, agrupados en forma aleatoria en dos lotes: testigo y tratado, con 15 animales cada uno. Durante los 100 días de duración del ensayo, recibieron una dieta compuesta por $70 \%$ de leche de vaca (entera en polvo) y $30 \%$ de harina de maíz. Realizado el análisis químico de la dieta para conocer su contenido mineral, se normalizaron los tenores de hierro y cobre adicionando $145 \mathrm{mg}$ de citrato de hierro/kg de alimento (para lograr 30 a $40 \mathrm{ppm}$ ) y $98 \mathrm{mg}$ de sulfato de cobre/kg de alimento para llevarlo entre 8 y $10 \mathrm{ppm}$ ). Además, a través del agua de bebida el lote tratado recibió $54 \mathrm{mg} / \mathrm{l}$ de TTMo de amonio $(P M=260,20$ con un $36,87 \%$ de Mo), ya que pruebas de toxicidad previas indicaron que fue la dosis ideal para provocar una molibdenosis experimental ${ }^{4,5}$. Teniendo en cuenta que por cada gramo de alimento ingerido se consumen $2 \mathrm{ml}$ de agua, este lote fue sometido a un desafío de 40 ppm de Mo dietario.

Al final de cada ensayo todos los animales fueron sacrificados por sangría a blanco efectuada por vía intracardíaca con jeringas heparinizadas, previa anestesia con hidrato de cloral vía ip. Realizada la necropsia se retiró el hígado, para su desecación y posterior análisis químico; también fueron separados los miembros posteriores para estudios químicos y anatomohistopatológicos.

Análisis químicos: las concentraciones de cobre en hueso y de cobre y molibdeno en hígado se realizaron sobre muestras desecadas a $100^{\circ} \mathrm{C}$ durante 48 horas, pesadas y luego disgregadas por digestión húmeda caliente nitro-perclórica; el hueso utilizado fue el fémur derecho de cada animal. Las determinaciones fueron efectuadas por espectrofotometría de absorción atómica con un equipo GBC Modelo $932 \mathrm{AB}$ Plus y los resultados expresados sobre materia seca. Los valores 
de referencia considerados para la química sanguínea y de los tejidos hepático y óseo fueron tomados de las publicaciones encontradas ${ }^{22,24}$.

Estudios anatomohistopatológicos: las características histológicas del hueso fueron evaluadas sobre el fémur izquierdo de cada animal, fijados en formol neutro al 10\%. En algunos casos se los descalcificó con una solución citrato de sodio-ácido fórmico y fueron deshidratados antes de ser impregnados e incluidos en parafina. Se realizaron cortes del tercio proximal de fémur con un espesor de 5 a 7 micrómetros, que fueron luego coloreados según técnicas clásicas de hematoxilinaeosina y tricrómica de Mallory. En otros casos el hueso se procesó sin descalcificación, utilizando la técnica de inclusión en resina plástica-metacrilato y cortes efectuados con cuchillas especiales para tejidos extraduros; se utilizó coloración de hematoxilina-eosina. Se describieron las características microscópicas encontradas y se tomaron fotomicrografías de las estructuras más representativas.

Análisis estadístico: los datos numéricos proporcionales (cobre y molibdeno) fueron tratados por análisis de la variancia (ANOVA) mediante un software estadístico (Statistix 3.5, 1991) para un diseño completo al azar a un criterio de selección, utilizándose un $\alpha=$ $5 \%$ para rechazar la hipótesis nula de igualdad.

\section{RESULTADOS}

Todos los animales tratados con TTMo de amonio desarrollaron gradualmente una sintomatología clínica similar. Hacia la primera semana comenzaron con defecaciones blandas, que se transformaron en diarreas frecuentes hasta el final del ensayo. Los animales que recibieron esta sal en el agua bebieron un promedio de $43 \mathrm{ml} / \mathrm{animal} /$ día a lo largo de toda la experiencia. No se registró disminución del apetito estimado desde el control realizado en la reposición diaria del alimento. La menor ganancia de peso corporal solo fue evidente en este lote, así como también la pérdida de estado general y aspecto hirsuto del pelaje.

Se registraron concentraciones de cobre significativamente menores $(\mathrm{p}<0,001)$ en el tejido óseo de los animales tratados con TTMo de amonio respecto a testigos (Tabla 1). En los animales con tratados con TTMo de amonio (Figura 1) se pudo evidenciar que altas concentraciones de Mo hepático se correspondieron con disminuciones significativas $(\mathrm{p}<0,001)$ de la reserva de cobre.

En los estudios anatohistopatológicos, los testigos exhibieron las estructuras normales de la placa de crecimiento del fémur, tanto en la coloración de hematoxilina y eosina (Figura 2) como con la técnica del metacrilato (Figura 3). En cambio, los animales sometidos a un alto ingreso de molibdeno mostraron engrosamientos de la placa epifisiaria, que se debió a un incremento desorganizado del cartílago de crecimiento, con masas de condrocitos hipertróficos aislados y zonas de cartílago seriado donde desaparecieron las columnas ordenadas de células cartilaginosas (Figura 4). La zona de
Tabla 1. Estadística descriptiva de la variable cobre del fémur (ug/g) en los dos lotes de ratas.

\begin{tabular}{lcc}
\hline estadígrafos & testigos $(\mathrm{n}=12)$ & TTMo $(\mathrm{n}=13)$ \\
\hline media $\pm \mathrm{DE}$ & $17,46 \pm 4,08^{\mathrm{a}}$ & $6,47 \pm 1,74^{\mathrm{b}}$ \\
$\mathrm{IC}<$ del 95\% & 14,87 & 5,42 \\
$\mathrm{IC}>$ del 95\% & 20,05 & 7,52 \\
coeficiente variación $(\%)$ & 23 & 27 \\
\hline
\end{tabular}

TTMo: tetratiomolibdato, DE: desviación estándar, IC: intervalo de confianza. Letras distintas indican diferencias significativas $(\mathrm{p}<0,05)$.

espículas óseas se presentó desorganizada, con pérdida de estructura, formando masas amorfas de tejido óseo inmaduro (Figura 5); las mismas lesiones fueron observadas mediante la técnica del metacrilato (Figura 6). En el lote con molibdenosis se observó en algunos animales engrosamiento del tejido óseo subperióstico, que comprometió toda la extensión de la diáfisis y metáfisis (Figura 7). Se verificó una falta de sustitución del tejido cartilaginoso y óseo primario por tejido óseo compacto maduro. Esto fue acompañado por formaciones de estructuras desorganizadas con abundante tejido fibroso, evidenciado por la técnica tricrómica de Mallory para fibras colágenas; así también se observó la presencia de abundantes osteoblastos y células osteoprogenitoras. Por otro lado, dicho engrosamiento fue acompañado por hemorragias subperiósticas en la zona de inserción muscular (Figura 8).

En los animales que recibieron TTMo de amonio, las alteraciones morfológicas descriptas en las inserciones ligamentosas, coincidentes con un desarrollo defectuoso del cartílago de crecimiento, sugieren ser producto de reacciones tisulares de expansión de la superficie transversal metafisiaria para soportar mejor el peso del cuerpo en huesos que tienen un incremento de deformabilidad ósea a las cargas.

\section{DISCUSIÓN}

En experiencias realizadas en ratones y ratas con deficiencia primaria de cobre se constató la aparición de anemia, baja actividad de ceruloplasmina y disminución de los niveles de cobre hepático ${ }^{14,25}$. En otros ensayos se encontró incremento del cobre hepático, especialmente en ratas machos que recibieron un exceso

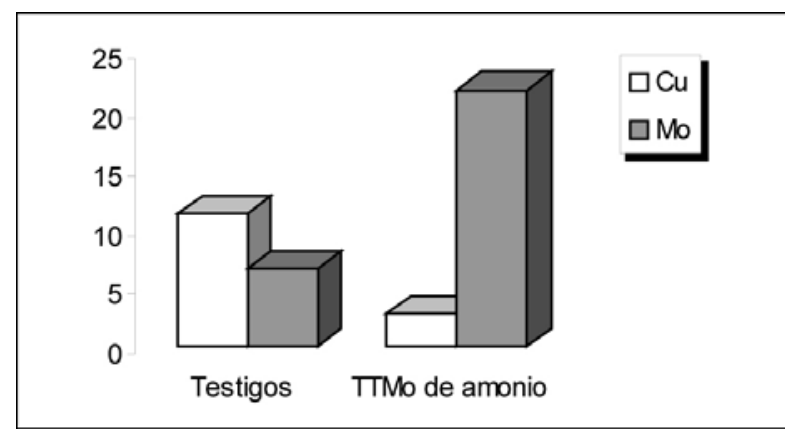

Figura 1. Concentraciones de cobre y molibdeno hepático, en ppm de materia seca. 
de molibdeno tal como fuera descripto en ovinos 1,11,29. Este hecho no ocurrió en nuestro ensayo pues los bajos tenores de cobre hepático fueron observados en el lote que recibió altos niveles de TTMo acompañado por un incremento del nivel de Mo en este órgano y que fueron similares a los observados en el tejido óseo.

Las alteraciones morfológicas encontradas pueden ser causadas por efecto de una reacción modelatoria ósea frente a la acción de cargas mecánicas deformantes, bajo nuestras condiciones experimentales particulares. La alta tasa de formación de colágeno exigida por esa situación puede derivar en alteraciones estructurales de su molécula, que de hecho se producen cuando tiene lugar la formación de hueso tramado como la de este caso. Teniendo en cuenta la teoría del mecanostato de Frost ${ }^{9}$, la reacción modelatoria pudo provocar engrosamientos metafiso-diafisiarios en las ratas con TTMo, pudiendo haber tenido lugar como un recurso homeostático compensatorio frente a una eventual reducción del módulo de elasticidad o de la capacidad de resistir estrés por parte del tejido óseo mineralizado (carga soportada por unidad de superficie de sección transversal). Estos fenómenos están orientados a optimizar el nivel de deformabilidad del tejido y/o del hueso frente a las cargas usuales; es la única variable esquelética que parece estar regulada cibernéticamente en los vertebrados óseos.

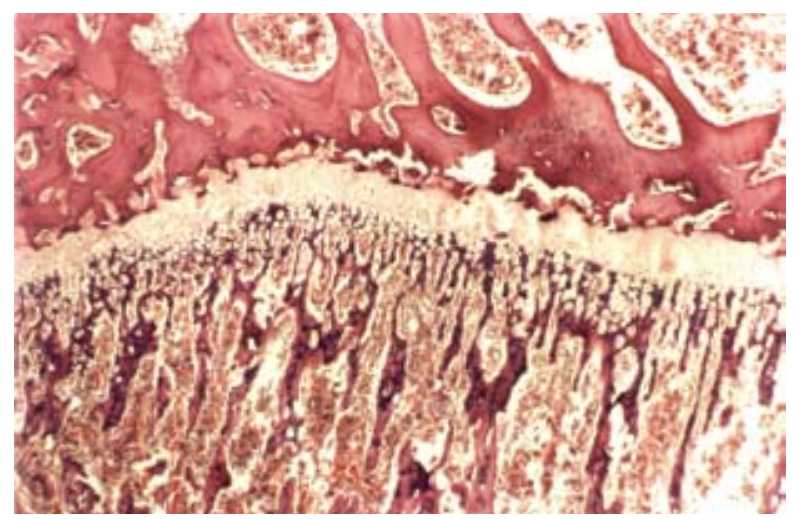

Figura 2. Rata control. Cartílago epifisiario normal en el extremo proximal del fémur (HyE, 40X).

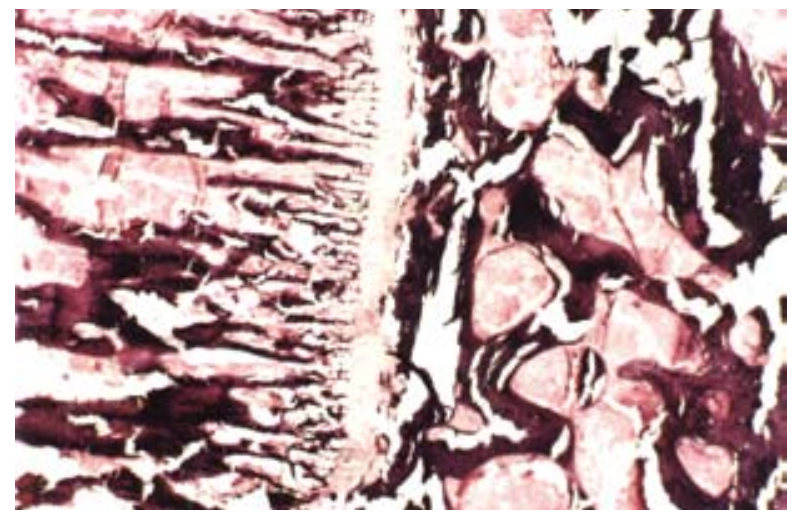

Figura 3. Estructura conservada del cartílago epifisiario proximal del fémur de un animal testigo, procesado mediante técnica sin descalcificación (metacrilato, 40X).
El engrosamiento subperióstico observado en nuestras ratas tratadas con TTMo estuvo acompañado por hemorragias que afectaron el tercio superior de la diáfisis, tal como fuera observado en corderos ${ }^{13}$. Las lesiones registradas en nuestras ratas recuerdan en algunos aspectos a lo observado en rumiantes con pasturas que contenían entre 5 y $20 \mathrm{mg}$ de $\mathrm{Mo} / \mathrm{kg}$ de materia seca, los cuales mostraron ensanchamientos de la placa de crecimiento y alteraciones de la osteogénesis del tejido esponjoso primario por estar resentida la actividad osteoblástica ${ }^{15}$. También se han descrito hemorragias subperiósticas en las inserciones musculares y fracturas óseas en corderos con molibdenosis ${ }^{13}$; microscópicamente a nivel del periostio se observaron hemorragias, edemas, producción de tejido osteoide y de granulación con alguna mineralización, pero sin alteraciones en la placa de crecimiento. Algunas de estas lesiones fueron vistas en ratas con tetratiomolibdatos ${ }^{27}$ y pueden estar relacionadas a un defecto básico en la síntesis de colágeno. Estas diferencias de lesiones observadas entre corderos y bovinos pueden ser, tal como fue sugerido para los animales de laboratorio, un reflejo de la diferencias anatómicas y posturales de

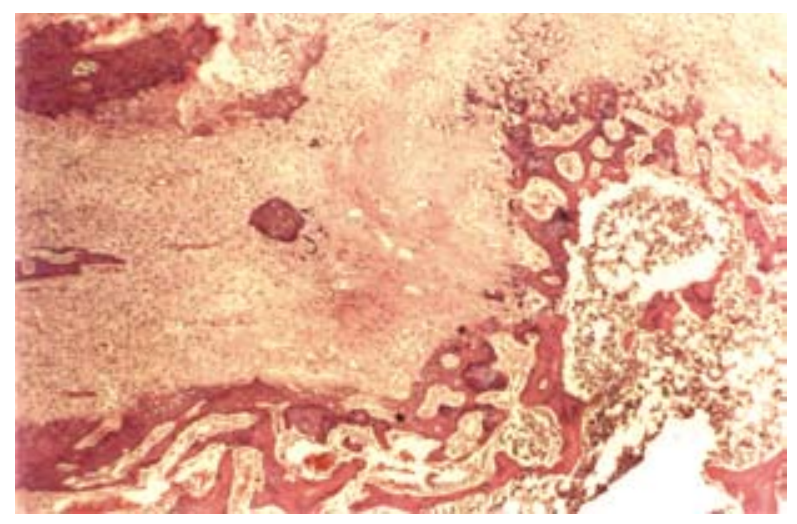

Figura 4. Rata tratada con TTMo de amonio. Crecimiento exagerado e irregular del cartílago epifisiario del extremo proximal del fémur. Desorganización de la zona de cartílago en reposo, seriado e hipertrófico. Se destaca la presencia de abundante tejido fibroso (HyE, 40X).

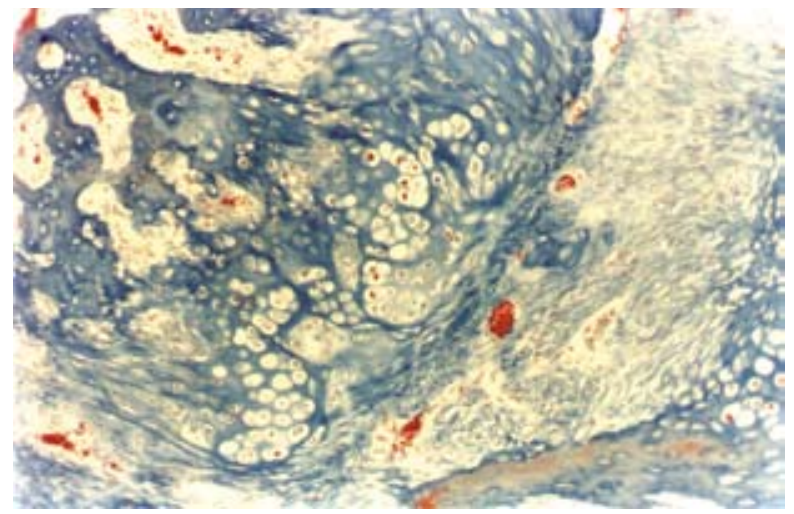

Figura 5. Rata con deficiencia secundaria de cobre. Crecimiento desorganizado e irregular del cartílago de la placa epifisiaria del extremo del fémur con masas de tejido óseo inmaduro (tricrómica de Mallory, 100X). 
estas especies. Las lesiones evidenciadas en nuestras ratas intoxicadas con TTMo señalan una participación muy importante del proceso de modelación ósea, que en el modelo experimental estudiado es mucho más trascendente que el de remodelación durante la etapa de crecimiento.

Los daños histológicos encontrados en los animales tratados con TTMo son coincidentes con los reportados en ratas ${ }^{27}$, donde se verificó multiplicación subperióstica de células osteogénicas con gran producción de hueso desorganizado, fenómenos que también fueron observados en rumiantes ${ }^{13}$.

En las ratas dosificadas con TTMo se observaron signos tempranos de anormalidad en el alineamiento e hipertrofia celular del cartílago epifisiario periférico, seguido por una completa pérdida de la arquitectura columnar en la placa epifisiaria y un excesivo número de condrocitos hipertrofiados y desorganizados, hecho similar a lo comunicado por otros autores ${ }^{27}$. Esto sumado a un incremento en la irregularidad de los bordes del tejido esponjoso primario, puede ser definido como

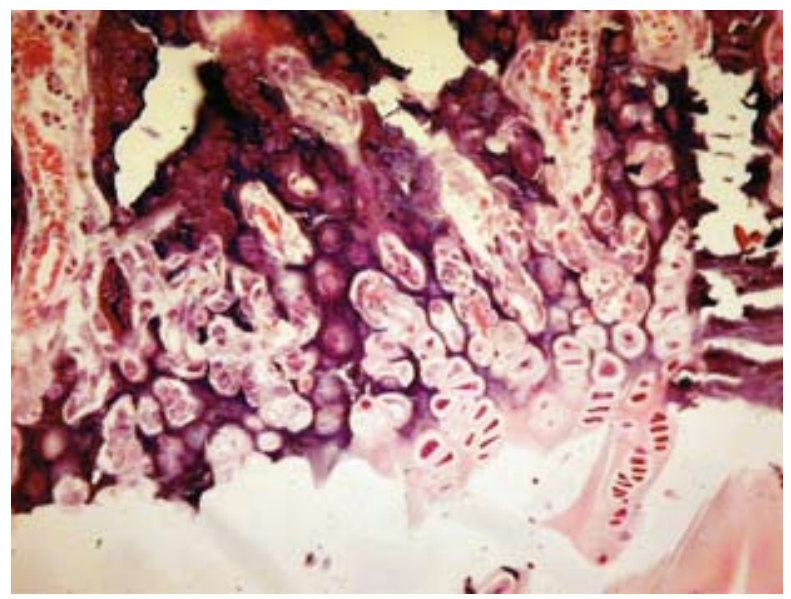

Figura 6. Cartílago epifisiario proximal del fémur de un animal con exceso de Mo. Masas de condrocitos hipertróficos y seriados con crecimiento desorganizado (metacrilato, 200X).

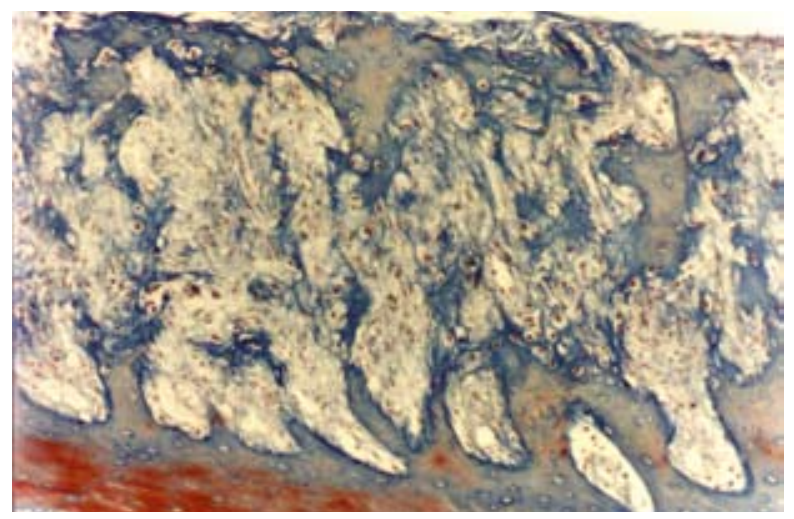

Figura 7. Animal con molibdenosis. Se destaca el engrosamiento subperióstico del fémur compuesto por masas de cartílago y tejido óseo inmaduro; en el centro de la imagen abundantes células osteoprogenitoras y tejido fibroso desorganizado (tricrómica de Mallory, 100X). una displasia cartilaginosa. La actividad celular incrementada en la placa de crecimiento contrasta con una osteogénesis disminuida a nivel del tejido esponjoso primario, con la presentación de condrocitos picnóticos rodeados por una excesiva matriz en la zona de mineralización, provocando la formación de bandas desorganizadas del esponjoso primario. También se observó, a nivel del periostio, un incremento en la osteogénesis periosteal cercana a la placa de crecimiento y en inserciones musculares y tendinosas, acompañadas por hemorragias subperiósticas. La mayoría de estas lesiones desaparecieron cuando los animales retornaron a una dieta normal.

Los resultados obtenidos en este ensayo con ratas coinciden con los observados en bovinos ${ }^{15,16}$, por lo que existe una alta probabilidad que la deficiencia condicionada de cobre inducida por un exceso de molibdeno no sea el mismo síndrome obtenido experimentalmente por una deficiencia primaria de cobre.

En conclusión, las lesiones óseas más importantes constatadas en los animales que recibieron TTMo de amonio consistieron en un engrosamiento de la placa epifisiaria de crecimiento, con masas de condrocitos hipertróficos y desaparición de su distribución en forma de columnas ordenadas de células. Hubo compromiso del tejido subperióstico con aumento de su espesor, acompañado de hemorragias en toda la extensión de la diáfisis y metáfisis femoral. No se verificó sustitución de material cartilaginoso y óseo inmaduro por tejido óseo maduro, comprometiéndose así la estructura normal del hueso; proceso acompañado por abundante tejido fibroso. El cambio observado puede ser interpretado como un efecto derivado de la reacción modelatoria ósea frente a la acción de las cargas mecánicas que el hueso tuvo que soportar, ya que las altas tasas de formación de colágeno exigidas por esta situación pueden derivar en alteraciones estructurales de su molécula.

Agradecimientos. A la Dra. Pamela G. Teibler, a la Lic. María Emilia Denegri y al Dr. Juan Carlos Sampietro, por la colaboración prestada.

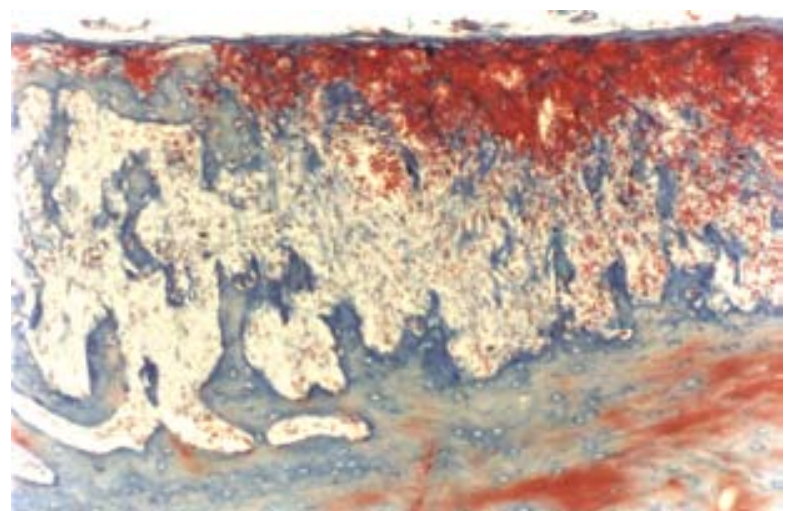

Figura 8. Rata tratada con TTMo. Se destaca la hemorragia en la zona del engrosamiento subperióstico con relación a zona de inserción muscular (tricrómica de Mallory, 100X). 


\section{REFERENCIAS}

1. Allen JD, Gawthorne JM. 1986. Involvement of organic molybdenum compounds in the interaction between copper, molybdenum and sulfur. $J$ Inorg Biochem 27: 95112.

2. Auza N. 1983. Le cuivre chez les ruminants. Une revieu. Ann Rech Vet 14: 21-37.

3. Borel JP, Randoux A, Maquart FX, Le Peuch C, Valeyre J. 1989. Bioquímica dinámica, Panamericana, Buenos Aires, p. 347.

4. Brem JJ, Pochón DO, Trulls HE. 1997. Ratas sometidas a dietas con exceso de molibdeno y deficientes en cobre. Anales de la Reunión de Comunicaciones Científicas y Tecnológicas de la UNNE, Corrientes (Argentina), p. 7174.

5. Brem JJ, Pochón DO, Trulls HE. 2000. Toxicidad del heptamolibdato y del tetratiomolibdato de amonio en ratas. Rev vet 10/11: 3-6.

6. Clarke NJ, Laurie SH. 1982. The copper-molybdenum antagonism in rumiants. Interactions of thiomolibdates with copper in aqueous media. Inorg Clin Acta 66: 35-38.

7. Clarke NJ, Laurie SH. 1986. The copper-molybdenum antagonism in rumiants. The formation of thiomolibdates in animal rumen. J Inorg Biochem 12: 32-43.

8. Dick AT, Dewey D, Gawthorne IW. 1975. Thiomolibdates and the copper-molybdenum sulphur interaction in rumiant nutrition. J Agric Sci Cambridge 85: 567-568.

9. Frost HM. 1987. The mechanostat: a proposed pathogenetic mechanism of osteoporoses and the bone mass effects of mechanical and nonmechanical agents. Bone Miner 1: $73-85$.

10. Gooneratne SR, Buckley WT, Christensen DA. 1989. Review of copper deficiency and metabolism in ruminants. Can J Anim Sci 69: 819-845.

11. Gooneratne SR, Hoell J, Gawthorne JM. 1981. Intravenous administration of thiomolybdate for the treatment and prevention of chronic copper poisoning in sheep. $\mathrm{Br} J$ Nutr 46: 457-468.

12. Harmer MA, Sykes G. 1980. Kinetics of the interconversion of sulfide and oxomolybdate species $\mathrm{Mo} \mathrm{O}_{\mathrm{x}} \mathrm{S}_{4-\mathrm{x}}{ }^{2-}$ in aqueous solutions. Inorg Chem 19: 2881-2885.

13. Hogan KG, Money DF, White DA, Walker R. 1971. Weight responses of young sheep to copper, and connective tissue lesions associated with the grazing of pastures of high molybdenum content. New Zeal J Agric Res 14: 687-701.

14. Igarza L, Quiroga MA, Agostini MC, Auza N. 1999. Modelo experimental para el estudio de la molibdenosis y de la deficiencia primaria de cobre en ratas. Acta Physiol Pharmac Terap Latinoam 49: 170-176.

15. Irwin MR, Poulos PW, Smith BP, Fisher GL. 1974. Radiology and histopathology of lameness in young cattle with secondary copper deficiency. J Comp Path 84: 611621.

16. Jubb KV, Kennedy PC. 1980. Patología de los animales domésticos, Hemisferio Sur, Montevideo, p. 397-405.
17. Kincaid RL, White CL. 1988. The effects of amonium tetrathiomolibdate intake of tissue copper and molybdenum in pregnant ewes and lambs. J Anim Sci 66: 3252-3258.

18. Mason J, Lamand M, Tresssol JC, Mulryan G. 1988. Studies of the changes in systemic copper metabolism and excretion produced by the intravenous administration of trithiomolybdate in sheep. Br J Nutr 59: 289-300.

19. Mason J. 1981. Molybdenum-copper antagonism in rumiants: a review of the biochemical basis. Irish Vet $J$ 35: 221-229.

20. Mason J. 1986. Thiomolibdates: mediators molybdenum toxicity and enzyme inhibitors. Toxicol 42: 99-109.

21. Mason J. 1990. The biochemical pathogenesis of molybdenum induced copper deficiency syndromes in rumiants: towards the final chapter. Irish Vet J 42: 18-21.

22. McDowell LR, Conrad JH, Ellis GL, Loosli JK. 1984. Minerales para rumiantes en pastoreo en regiones tropicales, Ed. Institute of Food and Agricultural Sciences, Florida University (Florida, USA), 92 p.

23. Mills CF, Dalgarno AC, Wenham G. 1976. Biochemical and pathological changes in tissues of Friesian cattle during the experimental induction of copper deficiency. $\mathrm{Br} J$ Nutr 35: 309-331.

24. Mitruka BM, Rawnsley HM. 1984. Guide to the care and use of experimental animals, Ed. Canadian Council on Animal Care, Ottawa, p. 83-91.

25. Prohaska JR. 1991. Changes in $\mathrm{Cu}, \mathrm{Zn}$-superoxide dismutase, cytocrome c-oxidase, glutathione peroxidase and glutathione transferase activities in copper-deficient mice and rats. $J$ Nutr 121: 355-363.

26. Rucker RB, Parker HE, Rogler JC. 1969. The effects of copper on collagen crosslinking. Biochem Biophys Res Comm 34: 28-32.

27. Spence JA, Suttle NF, Wenham G, El-Gallad T, Bremner I. 1980. A sequential study of the skeletal abnormalities witch develop in rat given a small dietary supplemented of ammonium tetrathiomolibdate. J Comp Path 90: 139-153.

28. Suttle NF. 1986. Copper deficiency in rumiants; recent developments. Vet Rec 22: 519-522.

29. Van Ryssen JB, Stielau WJ. 1981. Effect of different levels of dietary molybdenum on copper and Mo metabolism in sheep feel high levels of Cu. Br J Nutr 43: 203-208.

30. Wang ZY, Poole D, Mason J. 1988. Studies on the uptake and subsequent tissue distribution of $\left[{ }^{35} \mathrm{~S}\right]$ Trithiomolybdate in rat: effects on metallothionein copper in liver, kidney and intestine. J Inorg Biochem 33: 19-29.

31. Wang ZY, Poole D, Mason J. 1988. The effects of supplementation for the diet of young steers with Mo and S on the intracellular distribution of copper in liver and on copper fractions in blood. Br Vet $J$ 144: 543-551.

32. Ward GM. 1978. Molybdenum toxicity and hypocuprosis in ruminant: a review. J Anim Sci 46: 1078-1085.

33. Ward GM. 1991. Acceptable limits of molybdenum for ruminants exist. Nutr Health Beef 14: 22-27 